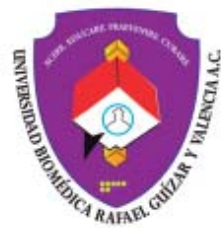

Vol. 8, Núm. 2

Julio-Diciembre 2021. pp. 96-98

doi: $10.35366 / 103088$

Cultural

\title{
La escultura autopoiética de Miguel Peraza Menéndez: desde una perspectiva psiconeurológica"
}

\author{
The autopoietic sculpture of Miguel Peraza Menéndez: \\ from a psycho-neurological perspective
}

\author{
Enrique Canchola Martínez*
}

${ }^{++}$Artículo tomado de:

https://www.sabersinfin.com/articulos/psicologia/28272-laescultura-autopoietica-de-miguel-peraza-menendez-desde-una-per con permiso firmado del editor.

\section{RESUMEN}

Desde el punto de vista neurofisiológico, la escultura de Miguel Peraza induce imágenes cerebrales esteroespaciales, que se van sucediendo e intercalando en distintas estructuras de la corteza cerebral sensorial, límbicas, talámicas y del tallo cerebral, integrando procesos emocionales y del pensamiento en el imaginario colectivo. Es parte de esa conexión necesaria donde habitan el yo, la conciencia y las emociones.

Palabras clave: Psico-neurología, conciencia, emoción, arte.

\section{ABSTRACT}

From a neurophysiological point of view, Miguel Peraza's sculpture induces stero-spatial brain images, which are successive and interspersed in different structures of the sensory, limbic, thalamic and brain stem cortex, integrating emotional and thought processes in the collective imagination. It is part of that necessary connection where the self, the conscience and the emotions inhabit.

Keywords: Psycho-neurology, consciousness, emotion, art.

\section{ANTECEDENTES}

En el presente artículo se pretende analizar desde las neurociencias la escultura de Miguel Peraza Menéndez, escultor mexicano perteneciente a la tercera generación de una familia de destacados escultores, también conocido como «el escultor de universidades».

La escultura de Miguel Peraza, por su construcción misma, induce un placer sensorial muy importante que permite construir elementos de experiencia

* División de Ciencias Biológicas y de la Salud, Universidad Autónoma Metropolitana-Iztapalapa y Departamento de Anatomía, Facultad de Medicina. UNAM, Ciudad de México, México.

Correspondencia:

Enrique Canchola Martínez

E-mail: enriquecanchola@yahoo.com.mx

Recibido: 14-09-2021. Aceptado: 04-11-2021

Citar como: Canchola ME. La escultura autopoiética de Miguel Peraza Menéndez: desde una perspectiva psiconeurológica. Plast Restaur Neurol. 2021;8 (2): 96-98. https://dx.doi.org/10.35366/103088

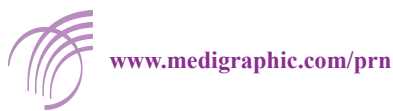


mental que evocan la emoción y la conciencia cognitiva ontogenética virtual, sincronizando la actividad cerebral, inductora de sentimientos que constituyen una utopía a la acción real del movimiento del inconsciente que se queda atrapado en los espacios de la morfología escultural.

\section{DESARROLLO}

La escultura de Miguel Peraza tiene el poder neuropsicológico de conectar muchos sistemas neuronales, relacionados con un afecto multidimensional de patrones endocrinos autónomos moduladores de eventos motores de placer acompañados de experiencia cognitiva subjetiva. ${ }^{2}$ Por donde el pensamiento se encarna en la escultura misma formando la base del aprendizaje emocional adaptativo, o dicho de otra manera, la escultura de Miguel Peraza representa una respuesta emocional coherente con elementos codificadores superiores para los significados emocionales conscientes e inconscientes.

Desde el punto de la neurociencia, la escultura de Miguel Peraza permite establecer una conexión entre los sistemas de integración neuronal arcaicos y modernos, donde habitan el yo, la conciencia y la supraconciencia (Figura 1).

Por otra parte, la escultura de Miguel Peraza despierta una emoción afectiva que construye estados emocionales subjetivos llamados qualia, que admiten interpretaciones profundas intrínsecas del pensamiento con gran valor

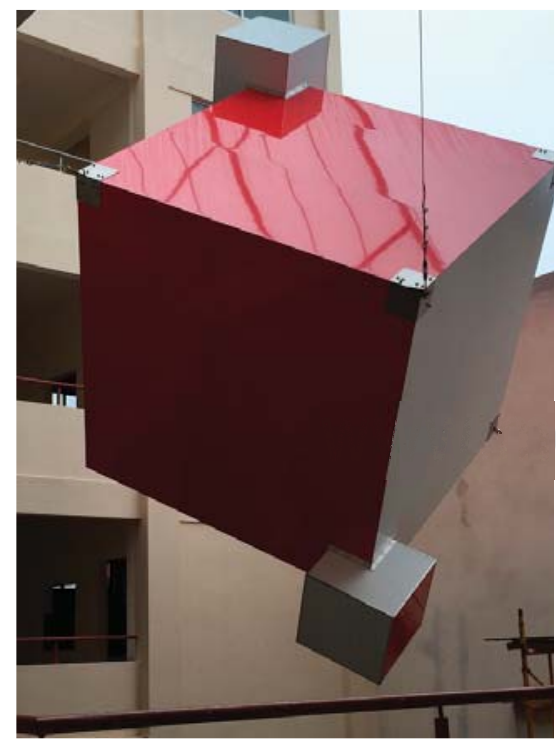

Figura 1: Escultura: Cubo de Guizar (2015). Universidad Biomédica «Rafael Guízar y Valencia». Xalapa, Veracruz, México.

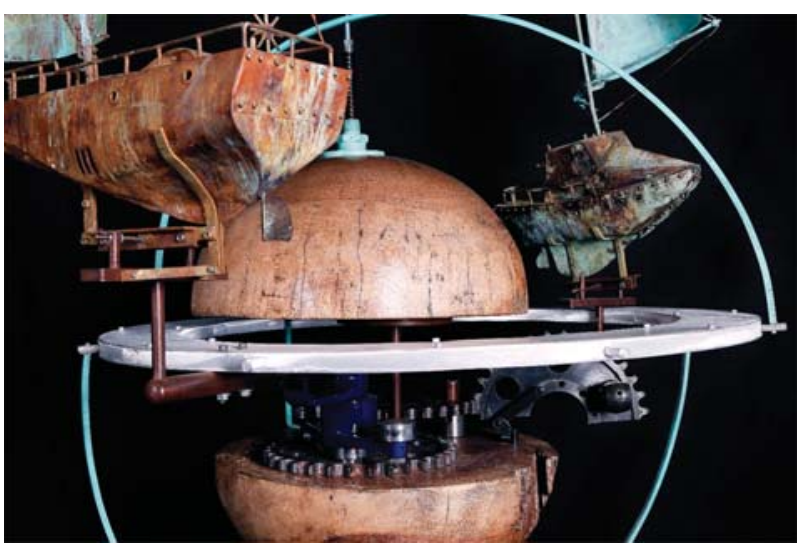

Figura 2: Escultura: Mundo Rueda (colección particular).

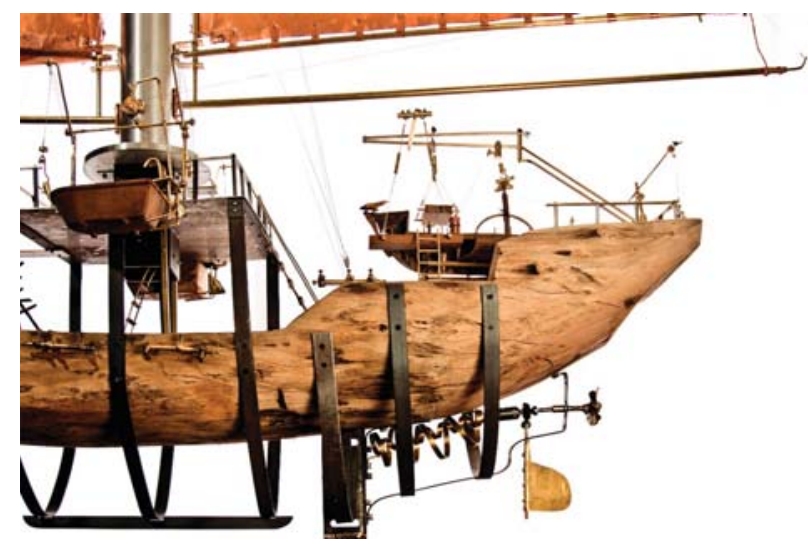

Figura 3: Escultura: Génesis (colección particular).

psicosensorial, con un significado personal a través de la reproducción de imágenes del yo activo, que transporta al cerebro a la percepción de lo lleno y lo vacío virtual, provocando conceptos integradores psicosociales que son cruciales para el procesamiento emocional (Figura 2).

Asimismo, la escultura de Miguel Peraza permite asociaciones mentales personales entre el observador y el objeto, extendiendo la riqueza de los qualia y sus aspectos relacionales con el sistema integral de las propiedades centrales de la conciencia, y con la extensión de la conciencia a la memoria del observador para construir un código mental que se va autoconstruyendo para generar imágenes sensoperceptuales en el cerebro, en donde las imágenes decodificadas, procesadas y reconstruidas representan la naturaleza diferencial del yo ubicado posiblemente en una conciencia efímera que da continuidad a la conciencia extendida y su relación con la escultura observada. ${ }^{3}$

Las esculturas de Miguel Peraza reúnen un conjunto heurístico consciente e inconsciente de belleza excep- 


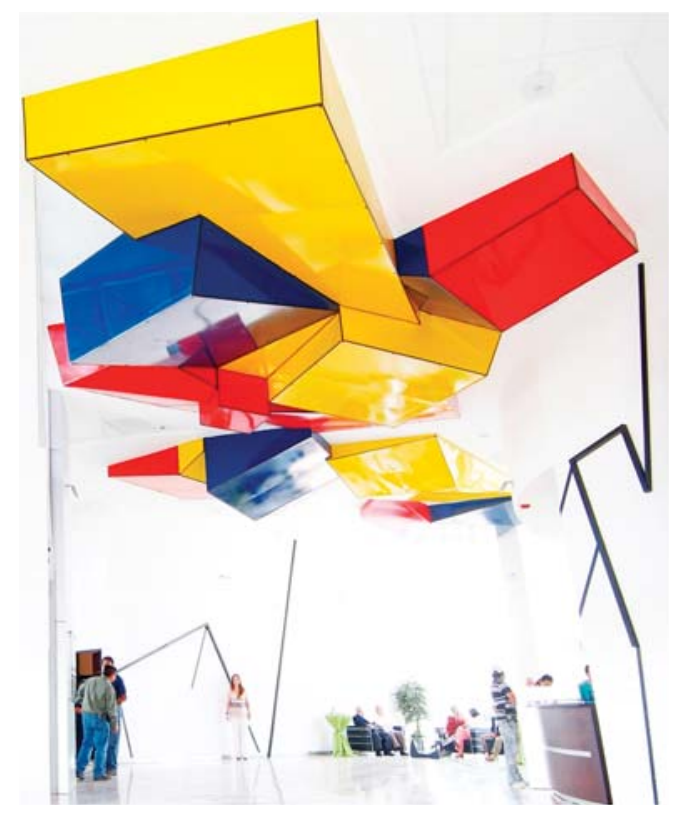

Figura 4: Escultura: Al interior del espejo. Colección Tecnológico de Monterrey, Campus Querétaro.

cional que inducen titileos mentales adictivos y reflexivos que se integran en las áreas perceptuales del cerebro y sus conexiones con las estructuras límbicas, donde se cimienta el conocimiento sin palabras del mundo y donde las interacciones con el mundo se dan por la analogía con el objeto observado, que intrínsecamente tiene la capacidad esencial para generar imágenes mentales en todas las modalidades sensoriales y plasmar una conciencia extendida, para lo cual sólo se requiere la interacción emocional con la imagen real o conjeturada. ${ }^{4}$

En la obra escultórica de Miguel Peraza se advierte la autorrepresentación psicocerebral que expresa eventos autobiográficos mediante imágenes representativas de la vida individual, con figuras que representan en forma especular un pasado que se recuerda y en un futuro mental que se anticipa, mediante las asociaciones emocionales personales plasmadas en su escultura (Figura 3).

Desde el punto de vista neurofisiológico, la escultura de Miguel Peraza induce imágenes cerebrales esteroespaciales, que se van sucediendo e intercalando en distintas estructuras de la corteza cerebral sensorial, límbicas, tallocerebelosas o talámicas, dependiendo del movimiento de los elementos esculturales, del ángulo espacial percibido o del lleno o vacío observado, ocasionando una respuesta psicoafectiva y una respuesta neurovegetativa que modifica la estructura endopsíquica del observador, lo que regula la descarga de la pulsión, según las condiciones de la realidad construida y del placer obtenido por medio de la escultura observada. La escultura de Miguel Peraza (Figura 4) con sus peculiaridades autopoiéticas, de abstracción, movilidad perceptual y juego mental visual del lleno y el vacío, así como su vinculación del yo con el objeto, produce estímulos supranormales que obligan al cerebro a construir una neurofenomenología de la forma, la profundidad y el color de la obra observada, obligando a que el pensamiento en activo agrupe los diferentes elementos de la obra y se activen redes neuronales para atrapar el mensaje subjetivo implícito en la escultura. ${ }^{5}$

\section{CONCLUSIÓN}

La escultura de Miguel Peraza tiene la capacidad de atrapar poderosamente la atención, porque su obra produce una actividad cerebral muy elevada al tratar de encontrar las diferentes imágenes y bosquejos figurativos mentales que producen el agrupamiento de los diferentes elementos que conforman el corpus escultural, que contiene elementos filosóficos, antropológicos, psicológicos y evocaciones de la inteligencia artificial.

\section{AGRADECIMIENTO}

El autor agradece al Dr. Abel Pérez Rojas (Tehuacán, Puebla), director de Sabersinfin.com, por la revisión del texto.

\section{REFERENCIAS}

1. Ramachandran VS. Interaction between colour and motion in human vision. Nature. 1987;328(6131):645-647. doi: 10.1038/328645a0.

2. Ramachandran VS, Rogers-Ramachandran D. The neurology of aesthetics. Scientific American Mind. 2006.

3. Papathomas TV. Art pieces that "move" in our minds--an explanation of illusory motion based on depth reversal. Spat Vis. 2007;21(1-2):79-95. doi: 10.1163/156856807782753958.

4. Zeki S. Artistici creativity and the brain. Science. 2001;293:51-52.

5. Zeki S. Art and the brain. Journal of Consciousness Studies. 1999;6-7:76-96.

Declaración de ética: Se cumplieron los requerimientos éticos.

Financiamiento: Este estudio no fue apoyado por subvenciones.

Conflicto de intereses: Los autores declaran que la investigación se llevó a cabo en ausencia de relaciones comerciales o financieras que pudieran interpretarse como un posible conflicto de intereses. 